\title{
A Framework for Optimizing Phytosanitary Thresholds in Seed Systems
}

\author{
Robin Alan Choudhury, Karen A. Garrett, Steven J. Klosterman, Krishna V. Subbarao, and Neil McRoberts ${ }^{\dagger}$
}

First and second authors: Plant Pathology Department, Institute for Sustainable Food Systems, and Emerging Pathogens Institute, University of Florida, Gainesville 32611; third author: U.S. Department of Agriculture-Agricultural Research Service, 1636 E. Alisal St., Salinas 93905; and first, fourth, and fifth authors: Department of Plant Pathology, University of California, Davis 95616.

Accepted for publication 14 July 2017.

\begin{abstract}
Seedborne pathogens and pests limit production in many agricultural systems. Quarantine programs help prevent the introduction of exotic pathogens into a country, but few regulations directly apply to reducing the reintroduction and spread of endemic pathogens. Use of phytosanitary thresholds helps limit the movement of pathogen inoculum through seed, but the costs associated with rejected seed lots can be prohibitive for voluntary implementation of phytosanitary thresholds. In this paper, we outline a framework to optimize thresholds for seedborne pathogens, balancing the cost of rejected seed lots and benefit of reduced inoculum levels. The method

requires relatively small amounts of data, and the accuracy and robustness of the analysis improves over time as data accumulate from seed testing. We demonstrate the method first and illustrate it with a case study of seedborne oospores of Peronospora effusa, the causal agent of spinach downy mildew. A seed lot threshold of 0.23 oospores per seed could reduce the overall number of oospores entering the production system by $90 \%$ while removing $8 \%$ of seed lots destined for distribution. Alternative mitigation strategies may result in lower economic losses to seed producers, but have uncertain efficacy. We discuss future challenges and prospects for implementing this approach.
\end{abstract}

The use of quality-declared seed is a critical component of disease and pest control in agriculture. Quality-declared seed are seed lots that are certified to have pathogen incidence or inoculum loads below established thresholds (Thomas-Sharma et al. 2016). Use of quality declared seed reduces the primary inoculum entering a field and contributes to lowering the overall epidemic severity of both mono- and polycyclic diseases. Programs at state and federal levels help prevent introductions of exotic pathogens into the United States, but strategies for slowing saturation by endemic pathogens are less commonly considered (Xing et al. 2017). Reintroductions of pathogen species pose an important risk of establishing novel genotypes or cryptic species that are difficult to distinguish from endemic pathogens (Atallah et al. 2010; Short and Gurung et al. 2015b). Managing these reintroduction events is critical to the longterm sustainability of U.S. agriculture.

Global trade has increased the movement of seeds and other plant material between countries, increasing the risk of movement of plant pathogens (Epanchin-Niell and Hastings 2010). Exotic pathogen introductions can have catastrophic effects on both natural and agricultural ecosystems, resulting in large economic losses from lost ecosystem services and reduced yield (Atallah et al. 2010; Cunniffe et al. 2016; Epanchin-Niell 2017; Short et al. 2015a). Introduction of exotic virulent strains of endemic pathogens can also severely disrupt agriculture (Atallah et al. 2010; Short et al. $2015 \mathrm{~b}$ ), and is difficult to regulate without a clear way to distinguish between the endemic and exotic virulence types. Differentiation

†Corresponding author: N. McRoberts; E-mail: nmcroberts@ucdavis.edu

Mention of trade names or commercial products is solely for the purpose of providing specific information and does not imply recommendation or endorsement by the U.S. Department of Agriculture. USDA is an equal opportunity provider and employer.

*The $\boldsymbol{e}$-Xtra logo stands for "electronic extra" and indicates that one supplementary figure and one supplementary table are published online.

This article is in the public domain and not copyrightable. It may be freely reprinted with customary crediting of the source. The American Phytopathological Society, 2017. is further complicated by the uncertainties of taxonomy, which frequently reassigns deviating groups of isolates to novel species (Inderbitzin and Subbarao 2014). Mis-identification of cryptic species as endemic pathogens allows for accidental introduction into new regions. Once a pathogen has established itself and is widely dispersed in a new region, eradication efforts are rarely successful (Epanchin-Niell and Hastings 2010). Endemic pathogens persist in the environment through several mechanisms. Many plant pathogens produce durable survival structures that can persist in soil or plant debris for years, and other pathogens have wide host ranges, with multiple host species that can act as green bridges between different regions.

Phytosanitary thresholds are one way to mitigate the introduction of exotic strains and to reduce the overall amount of pathogen inoculum moving into a region, by limiting the amount of allowable pathogen inoculum in or on affected plant parts (Gabrielson 1988; Kuan 1988; Roberts 1999; Russell 1988; Schaad 1988; Stace-Smith and Hamilton 1988). Exotic strains may be introduced from both domestic or international sources; as such, the certification processes should occur wherever the seeds are produced.

While setting a threshold of zero detectable pathogen density or incidence would be desirable, it is often impractical for endemic pathogens. At the same time, having no limit on endemic pathogens can result in economic losses to farmers in the short run, and increased breakdown of resistance genes in the long run. Programs for the development of quality-declared seed with lower pathogen levels can help reduce regional disease levels and increase the useful life of resistance genes (Thomas-Sharma et al. 2016). Such programs would benefit from strategies to develop phytosanitary thresholds for endemic pathogens that balance the need for adequate quantities of reasonably priced seed, with the need for reduced pathogen levels.

Here we outline a framework that offers guidance for developing suitable phytosanitary thresholds using available data, to reduce multiple reintroductions of endemic pathogens on seeds. We offer an outline for estimating the effects of thresholds at individual field and regional scales, and we describe the costs and benefits of establishing these thresholds. Thresholds derived from empirical analyses such as those used here need to be recalibrated as changes 
in agricultural and climatic conditions (such as host density and environment) occur and as new data become available from additional seed testing.

Our objectives are to (i) develop a general framework for establishing phytosanitary thresholds, given the common limitations on data availability, for scenarios where nonzero thresholds are useful; (ii) explore the integration of landscape epidemiology for establishment of phytosanitary thresholds; and (iii) apply this framework to spinach downy mildew, an important endemic pathogen of spinach in the United States and globally, that is repeatedly reintroduced via infested seeds.

\section{WHEN ARE NONZERO PHYTOSANITARY THRESHOLDS USEFUL?}

Nonzero phytosanitary thresholds limit the amount of pathogen inoculum allowed on infested plant parts. Nonzero phytosanitary thresholds are most useful in systems where an endemic pathogen is repeatedly reintroduced on seeds or other plant parts (Fig. 1). These reintroduction events can introduce new virulent genotypes or mating types, allowing the pathogen to adapt more readily to control strategies such as resistant varieties or fungicides. Developing a universally accepted threshold may require years of laboratory and in-field experiments that demonstrate the link between pathogen levels and economic damage from a disease (Kuan 1988; Wu and Subbarao 2014), and many diseases are difficult to control through phytosanitary thresholds alone (Grogan 1980). Some questions can help stakeholders decide if a phytosanitary threshold would be useful for their pathosystem (Fig. 1).

Is the pathogen exotic? While nonzero phytosanitary thresholds help reduce the amount of inoculum introduced into a region, they do not fully remove all inoculum. In many cases, the most economic and effective control for exotic or highly virulent pathogens is with an exclusion quarantine (Epanchin-Niell 2017). Using a nonzero phytosanitary threshold for an exotic pathogen is counterproductive, and increases the risk of future outbreaks and increased

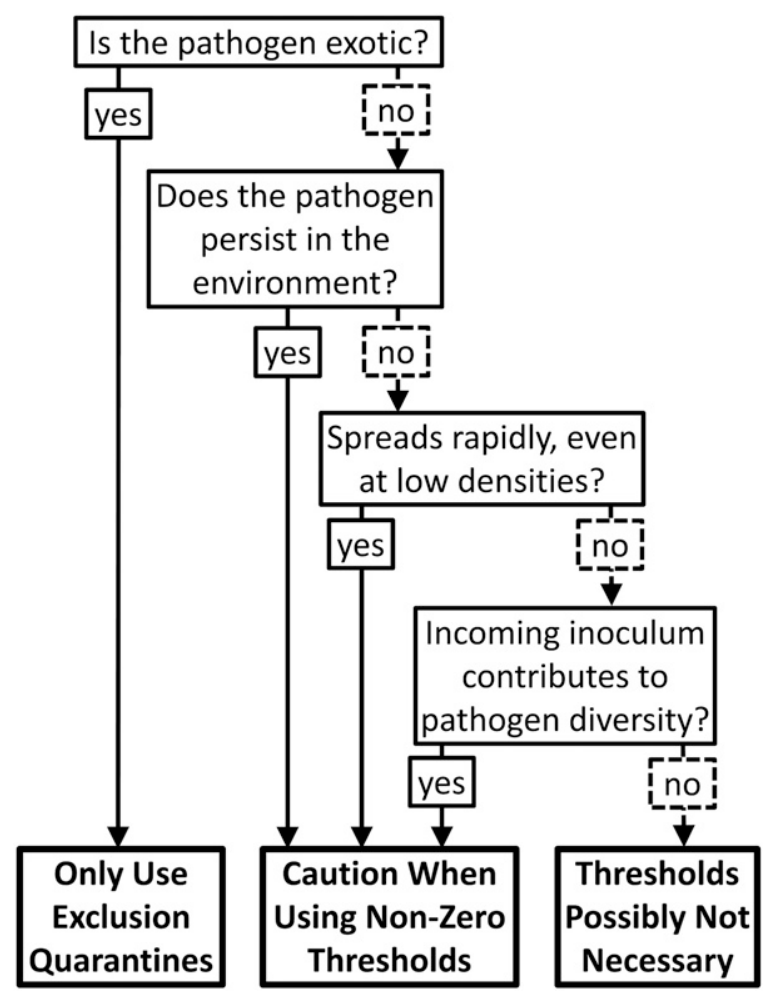

Fig. 1. Decision tree for whether to implement nonzero phytosanitary thresholds. economic losses. These threats are compounded in systems involving internationally quarantined agents, where the risk of regional colonization is not only yield loss but also reduction or loss of trade (Brennan et al. 1992; Islam et al. 2016; Marshall et al. 2003; Stansbury et al. 2002).

Does the pathogen persist in the environment? Pathogens that can produce durable survival structures may persist in soils for several growing seasons, allowing for the accumulation of inoculum over time (Atallah et al. 2012). Nonzero phytosanitary thresholds that allow pathogen inoculum from infested seed lots into fields can create persistent problems for production (Short et al. 2015a). Nonzero phytosanitary thresholds for pathogens that form durable structures should account for the actual use of different agronomic practices, such as rotation strategies and host susceptibility.

Does the pathogen spread rapidly, even at low densities? Developing an effective long-term solution for easily-spread pathogens can also be hindered by the effects of secondary inoculum contributing to the regional epidemic (Fig. 2). Early applications of seed thresholds may appear to fail if the effects of secondary inoculum are large, allowing disease to develop in plants grown from quality declared seeds (Grogan 1980). Implementing the threshold consistently over a wide area along with other control efforts to reduce secondary inoculum can eventually cause disease incidence to decline. However, this effect depends on whether the combined mitigation tactics can reduce the basic reproductive number $\left(\mathrm{R}_{0}\right)$ to below one. If the overall reproductive number remains above one, outbreaks will continue to occur. One example of a successfully implemented disease threshold is in lettuce mosaic disease in coastal California, where a combination of quality declared, vector management, removal of alternative weed hosts, and a host-free period in the winter effectively controls disease outbreaks (Grogan 1980; Wisler and Duffus 2000). These combined efforts have reduced the severity of lettuce mosaic disease in coastal regions where it once caused severe yield loss.

Does the incoming inoculum contribute to pathogen diversity? Many plant pathogens have spatially structured populations (Goss 2015; Grünwald and Goss 2011). Movement of infested seed may introduce novel genotypes, increasing local diversity and degrade the efficacy of control strategies such as host resistance and pesticides. The genetic structure of many pathogens

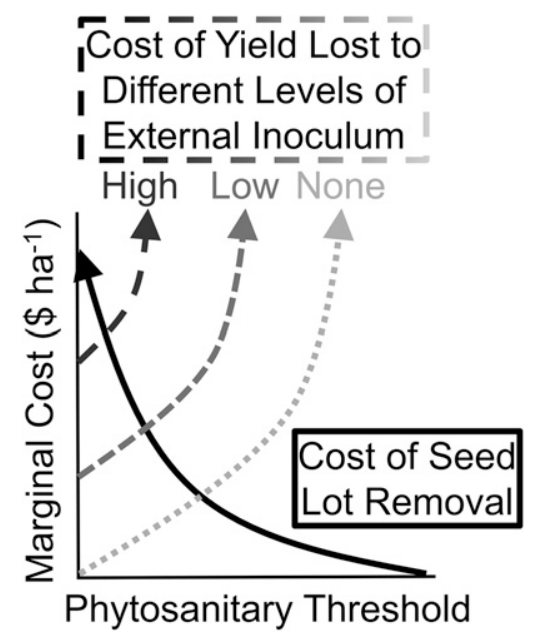

Fig. 2. Diagram of the trade-off inherent in selection of a phytosanitary threshold. Higher thresholds result in a lower marginal cost of seed lot removal with strict phytosanitary thresholds and the marginal costs of yield loss depending on whether there is high, low, or no external inoculum, inoculum that comes from non-seed sources such as soil or wind-blown inoculum. The threshold where the combined costs are lowest would be a candidate for optimizing profit in the short run. In the long run, more effective regional management can shift the regional inoculum level. 
is poorly understood, making it difficult to assess the extent of increasing genotypic diversity. The presence of a reproductive stage on infested seed may pose represent a serious threat for producers because of the risk of generation of novel genotypes through recombination and selection (McDonald and Linde 2002).

\section{COSTS AND BENEFITS OF PHYTOSANITARY THRESHOLDS}

An ideal phytosanitary threshold would maximize the total amount of inoculum removed, minimize the number of seed lots removed because of the threshold, all while maintaining economic disease control. The tradeoff between lost seed lots and contaminated seeds removed is difficult to balance because phytosanitary thresholds can vary in their efficacy depending on the region. For example, lettuce mosaic virus can be controlled in the Netherlands by using seed lots certified to have 0 infested seeds in 2,000, while in California the necessary threshold is 0 in 30,000 (Kuan 1988). Differences in climate, agronomic production density, and vector populations create greater risk from a small number of infested seeds in California.

Costs. Establishment of effective phytosanitary thresholds requires thorough field and laboratory work. While some thresholds are developed over the course of several years and based on numerous studies, more frequently they are arbitrarily determined, or based on limited field observations (Kuan 1988). One problem in establishing thresholds is that the terms of international trade, ratified by the World Trade Organization (and previously by the General Agreements on Tariffs and Trade-GATT), specifically prohibit participating countries from erecting arbitrary barriers to trade (Henson and Loader 2001). Phytosanitary concerns are legitimate reasons to impose trade import bans, or actions to reduce risk by the exporting country, but if thresholds on seed contamination are set arbitrarily they are subject to challenge.

Seedborne pathogens heavily affect agriculture around the world. In the developing world, they are especially important for crops that are vegetatively propagated, which are the staple carbohydrate for many subsistence farmers (Buddenhagen et al. 2017; Sperling et al. 2013; Thomas-Sharma et al. 2016; Xing et al. 2017). While there is a pressing need to reduce incoming inoculum on infested seed lots, strict thresholds may be too costly to implement. A phytosanitary threshold that aims to remove all inoculum may be unattainable for these settings, resulting in no quality-declared seed at all. A nonzero threshold may provide many benefits by reducing levels of infection while still being economically viable for smallholder farmers.

Whether evidence-based or precautionary, all phytosanitary policies have costs. In addition to short-term costs, such as the cost of removed seed lots or the cost of testing procedures, there are potential long-term costs. Broadly, the impacts of these wider longterm costs range from the purely private to the public, e.g., lost planting opportunities, reduced seed supply, and potential retaliatory quarantines. If the policies are ineffective, these costs may compound over time as pathogen prevalence increases in a region as a consequence of continued import and secondary increase.

Benefits. The potential benefits of a phytosanitary threshold range from public to private and may be considerable when summed over large areas and long timespans. The benefits associated with phytosanitary thresholds depend on the spatial and temporal scales considered. At a small temporal and spatial scale, phytosanitary thresholds help to reduce the amount of inoculum introduced into a single field, reducing the risk of economic losses due to disease. Over time, this reduction in inoculum can help reduce regional disease pressure by reducing genotypic diversity of the pathogen and inoculum build-up due to repeated disease outbreaks. Pathogen introduction events can directly introduce new virulent strains from other regions, or can increase the population diversity by introducing new mating types or sexual structures. Minimizing the genotypic diversity of the pathogen population stabilizes the efficacy of control strategies. The risk of development of pesticide resistance and host resistance-breaking strains increases with large increases in pathogen populations (McDonald and Linde 2002; Stukenbrock and McDonald 2008). Some of these effects are only seen when considering an entire landscape of susceptible hosts.

\section{MEASUREMENTS OF INOCULUM ON SEED}

Being able to accurately and consistently quantify pathogen presence in seed lots is important for the development of effective phytosanitary thresholds. The sampling theory associated with this process is well developed (Geng et al. 1983; Russell 1988), and calculating a necessary sample size given accepted error rates is straightforward (Geng et al. 1983; Madden et al. 2007). However, using these measurements to construct an effective phytosanitary threshold can be challenging.

Seed assays vary based on the type of pathogen being detected (fungal, bacterial, and viral) and the sensitivity required. Some assays determine inoculum density, a measure of how much inoculum is present per unit of seed (Fig. 3). The density of bacterial seed pathogens is frequently quantified as colony forming units (CFUs) per gram of seed (Gitaitis and Walcott 2007; Schaad 1988). Other assays directly detect the contamination status of individual seeds, and are frequently expressed as the proportion of seeds affected, a measure of incidence (Pryor et al. 1994). Both density and incidence type assays can be expressed as presence/absence assays, where, in the case of density measures, the population density scale is partitioned into two classes, zero and all population densities greater than zero. Any assay expressing results at the seed scale can also be used to generate incidence (i.e., presence/absence) data at the scale of the seed lot. Such seed lot scale results can be useful in cases where strict control of pathogen inoculum levels are necessary to maintain effective disease management.

Each seed assay has advantages and disadvantages, given different pathosystems. In the absence of automated image analysis systems, it might be effectively impossible to conduct visual assays of individual seeds when sample sizes are large, making incidence assays unusable. For pathogens with high reproduction rates, assays based on pathogen inoculum density may not be more informative or useful than incidence assays, since reproduction by the pathogen, once introduced into the system, will quickly minimize variation in primary inoculum on seeds. Of the three assay types, contamination density may be the most difficult to use for routine application of phytosanitary thresholds. Density assays rely on accurate identification of pathogen propagules, which may be difficult due to excess contamination, or the presence of phenotypically or genetically similar pathogenic and nonpathogenic strains.

Irrespective of the type of data collected or the pathosystem that is the target of the screening activity, an operational decision rule is required in order to sort seed lots into "accept", "reject", and "retest" categories. The decision rule will always be applied based on a sample drawn from the seed lots, and the long-term statistical performance of the decision will depend on how representative the sample is. Researchers should re-evaluate the initial decision rule as new data accumulate from continued testing.

The capacity to use thresholds effectively depends on the relationship between the intensity of contamination and the distribution of contaminated seeds among seed lots. Ideally, a high proportion of pathogen inoculum would be concentrated in a relatively small number of seed lots, so that these can be removed at low cost, while the majority of lots have a low level of contamination. If the cumulative proportion of seed lots is plotted against the level of contamination, the resulting relationship should be convex for the threshold approach to have a high chance of success. In this case, the highly-contaminated lots can be excluded by setting a relatively high threshold, allowing most seed lots to pass. In cases where inoculum is evenly distributed across seed lots or most seed lots have heavy contamination, the cumulative distribution of seed lots against 
contamination intensity is concave. In that case, a relatively high proportion of seed lots is excluded even for a lenient threshold level.

\section{LANDSCAPE EPIDEMIOLOGY OF PHYTOSANITARY THRESHOLDS}

Landscape epidemiology in plant pathology is typically concerned with the short- or long-distance transport of secondary inoculum, allowing neighboring regions of hosts to become infected (Meentemeyer et al. 2012). Pathogen propagules associated with seeds often serve as primary inoculum, directly affecting the initial disease status of a host. Estimates of the number of infection events that might occur under different scenarios can inform choices among different management options. Considering the consequences from seed phytosanitary thresholds at a landscape (or regional) level is important because the aggregate costs and benefits at such scales are likely to be the primary drivers of decisions regarding seed inspection rules.

There is frequently not enough field or laboratory data to state definitively what the appropriate threshold should be; this makes setting evidence-based policy problematic (Kuan 1988). Data might simply be too difficult or costly to collect. Separating the effect of seed contamination on disease levels from other confounding variables may be experimentally challenging. Secondary inoculum or differences in regional environmental effects or host populations may cloud the effects of seedborne inoculum on regional epidemic progression (Grogan 1980; Kuan 1988). With the difficulties in establishing evidence-based policy, the temptation is to use a general precautionary approach, but this can be overly restrictive on trade.

The method of Fermi approximation (Edge and Dirks 1983) can be used to obtain probable order-of-magnitude estimates of the level of infection that likely would arise from a given level of seed contamination. Although the estimates are imprecise, these methods are useful when there is relatively little direct information about a subject. The estimation of infection levels may be distorted if there are multiple sources of primary inoculum (e.g., overwintering infected hosts, durable survival structures in soil or field debris, neighboring infected fields, etc.).

If pathogen population density per seed is measured, we can obtain a Fermi approximation of the total potential infections $(I)$
INFESTED SEED LOT
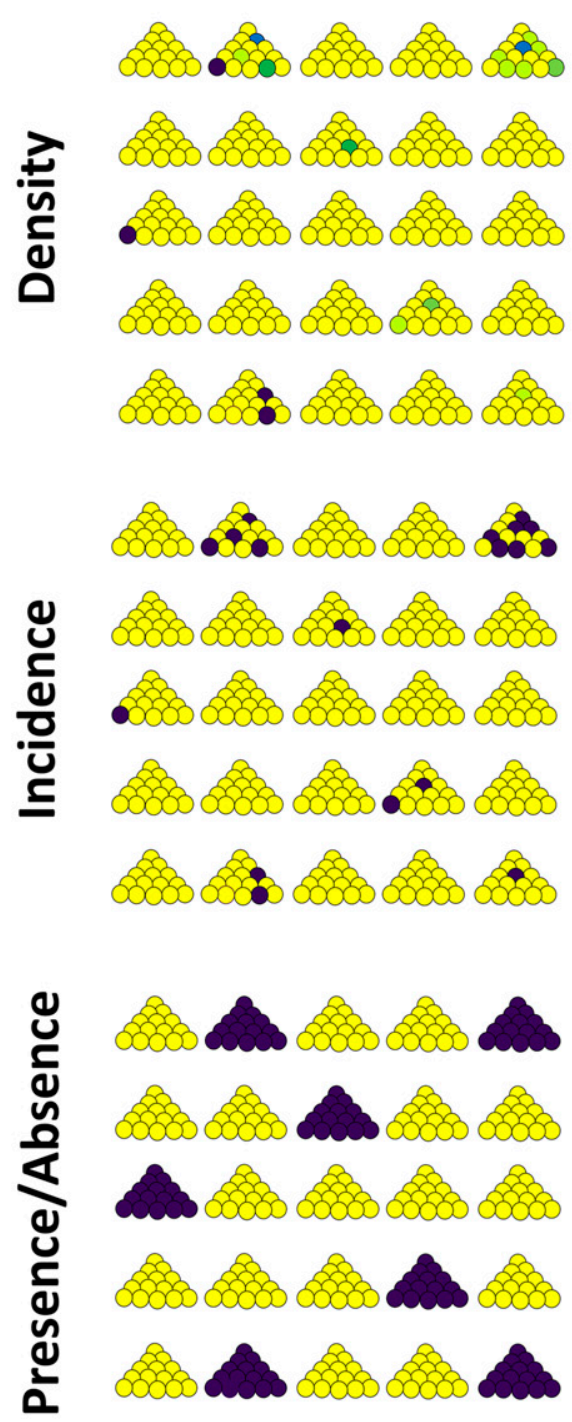

HISTOGRAM
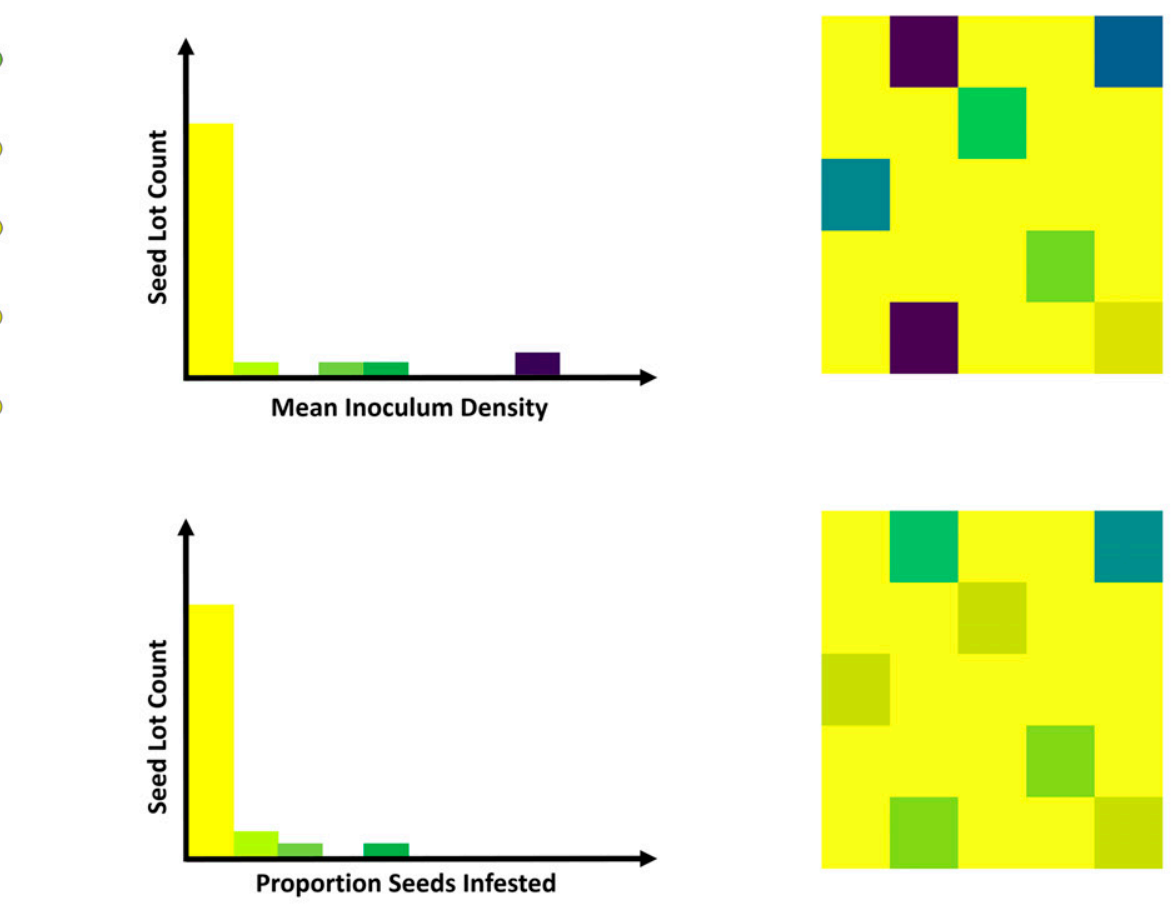

\section{PREDICTED LANDSCAPE}
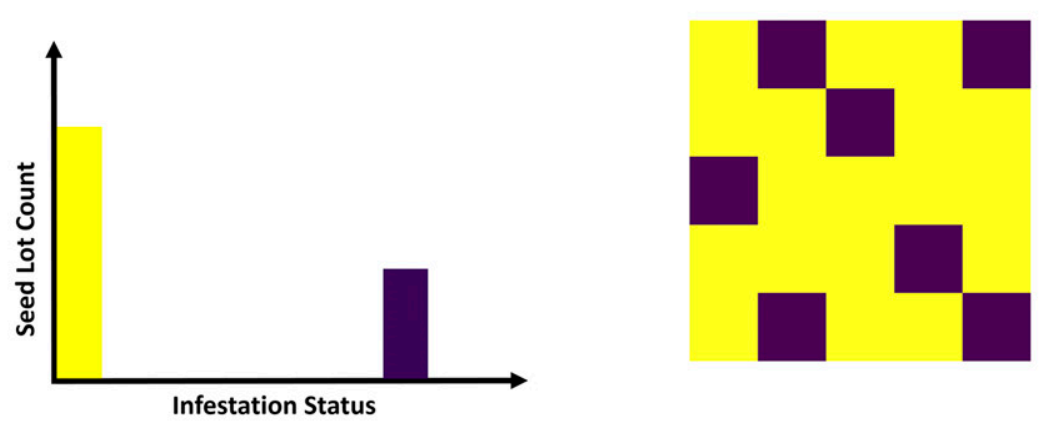

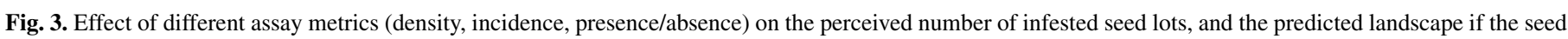

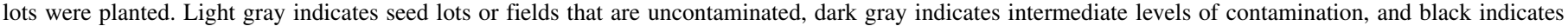
heavy levels of contamination. 
across a landscape from infested seed lots, starting with estimates of the inoculum load per seed based on individual samples:

$$
x_{t}=\frac{x_{i} *\left(\frac{t}{s}\right)}{l}
$$

where $x_{t}$ is the estimated total number of propagules per seed in the seed lot, $x_{i}$ is the number of observed propagules reported from the subsample, $t$ is the total volume of sample, $s$ is the volume of subsample analyzed, and $l$ is the total number of seeds tested in the sample. Equation 1 accounts for differences in the sampling proportion each sample represents across seed lots of different sizes. With data for the average inoculum load per seed, and the proportion of infected seed lots obtained from sample data, the Fermi approximation for the number of infections arising from infected seed $(I)$ is given by

$$
I=\bar{x}_{t} \times S_{i} \times R_{S} \times R_{G} \times R_{i} \times A_{T}
$$

where $\bar{x}_{t}$ is the mean number of propagules per seed across the infested seed lots, $S_{i}$ is the proportion of seed lots that are infested, $R_{S}$ is the seeding rate per unit area, $R_{G}$ is the germination rate, $R_{i}$ is the infection rate (infections per propagule), and $A_{T}$ is the total area of susceptible plants. If we assume that the seeding rate, germination rate, infection rate, and acreage of susceptible crop are constant between seed lots that are heavily and lightly infested, then we can simplify the expression to represent a proportional risk factor $(\theta)$, or

$$
\theta=\bar{x}_{t} \times S_{i}
$$

If we assume that management strategies like seed lot removal affect the total number of pathogen propagules but do not affect the pathogenity of the remaining propagules, we can use $\theta$ to estimate the relative effect of different management strategies by comparing the untreated proportional risk factor $\left(\theta_{u}\right)$ and the treated proportional risk factor $\left(\theta_{t}\right)$ to determine the proportional difference in effect of different management strategies.

There are a number of open questions beyond estimating the number of total infections occurring over a landscape. While pathogen density assessments determine an average inoculum load across a set of tested seeds, inoculum is frequently unevenly distributed (Danielsen et al. 2004), with some seeds being heavily infested and others being relatively clean. Understanding how this uneven inoculum distribution may be used in predicting the spatiotemporal progress and aggregation of the disease in affected fields is an open question (Fig. 3). Many pathosystems, including some seed systems (Roberts 1999), have epidemiological thresholds, where an initial level of infection from seeds is low enough to keep epidemics from spreading beyond the area of initial infection (Gilligan and van den Bosch 2008). Understanding the factors that lead to locally-contained versus widely-spreading epidemics could help to set more economically reasonable phytosanitary thresholds.

\section{CASE STUDY: SPINACH DOWNY MILDEW}

Downy mildew, caused by the obligate oomycete pathogen Peronospora effusa (Grev.) Rabenh (formerly P. farinosa f. sp. spinaciae) (Choi et al. 2007), is the most important disease of spinach worldwide (Correll et al. 2011), and is a serious threat to organic crop production (Klosterman 2016). Disease symptoms are characterized by chlorotic lesions on leaves, and severe symptoms can lead to postharvest decay, resulting in reduced quality and shelf life of fresh market types (McKay et al. 1992). Most spinach production in the United States occurs in California and Arizona, primarily in the Salinas, Imperial, and Yuma Valleys (Koike et al. 2011). In the fresh market sector, organic spinach represents about one third of total production in the United States (USDA-NASS 2015). Organic spinach cannot be sprayed with synthetic pesticides, so growers rely heavily on resistant varieties to prevent disease. Peronospora effusa is endemic in California with annual epidemics that intensify as production increases during each season (Choudhury et al. 2016). New, virulent $P$. effusa races have emerged at an exponential rate over the last two decades (Correll et al. 2011). This rapid emergence of new races has disrupted spinach production by forcing spinach breeders to focus on resistance traits when developing new varieties (Correll et al. 2011). The escalation in the appearance of pathogen races has occurred at the same time as other changes in fresh market spinach production, such as the use of wider planting beds, increased seeding rates, and the use of overhead irrigation (Correll et al. 2011; Koike et al. 2011).

The multiple simultaneous changes within spinach production over the last 20 years make it difficult to discern which factors most significantly influence the emergence of new pathogen races. Irrespective of its causes, an increasing diversity in $P$. effusa has led to increased disease outbreaks, allowing the pathogen more rapidly to overcome resistance genes deployed in new varieties. While some oomycetes can undergo changes in population diversity through asexual reproduction alone (Lamour et al. 2012), evolutionary models suggest that pathogens capable of asexual and sexual reproduction represent the highest risk for developing higher population diversity and overcoming resistance genes (McDonald and Linde 2002). A recent population study provides some evidence for sexual reproduction of $P$. effusa (Lyon et al. 2016), and identifies common genotypes in geographically diverse areas, suggesting either interregional dispersal or a common source of $P$. effusa.

The recent detection of viable oospores in commercial seed lots raises the concern that new races of spinach downy mildew might be arising from sexual reproduction (Kunjeti et al. 2016), but the extent to which this is occurring in a given geographic area is not clear. New races may already be present in the population and their presence simply revealed after the deployment of new resistant cultivars that provide high levels of selection against other genotypes (Correll et al. 2011). Reducing the number of oosporeinfested seed lots entering the production system each year may benefit growers and seed producers by delaying or stopping the emergence of new pathogenic races.

Oospore infested commercial seed lots. Eighty-four untreated, organic spinach seed lots from multiple commercial seed producers were tested for the presence of oospores in a procedure similar to that described in Kunjeti et al. (2016) (Fig. 4). Briefly, 500 or 1,000 seeds were placed into a 50-ml Falcon tube with $20 \mathrm{ml}$ of sterile deionized water. Tubes were fixed onto a Fisher pulsing

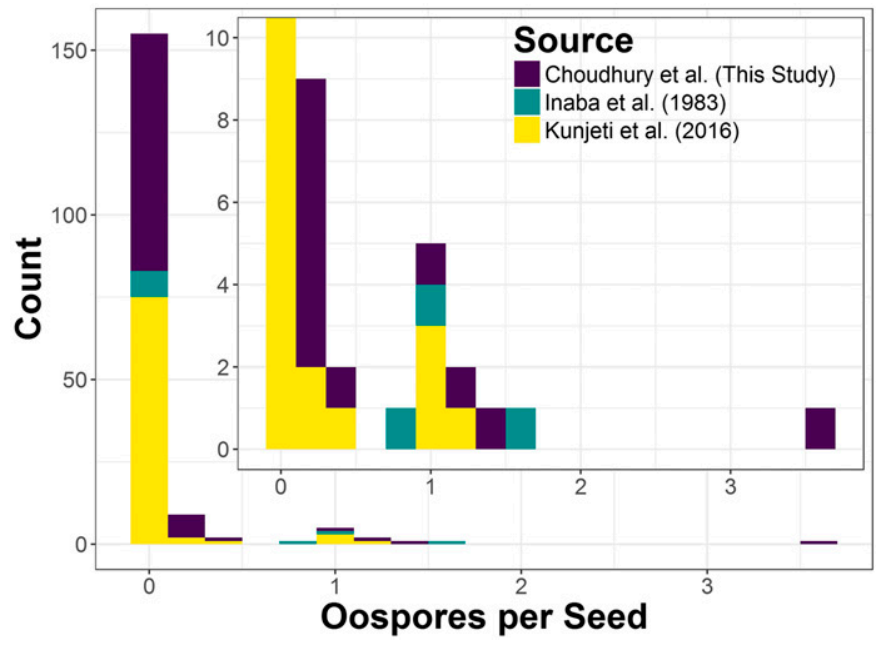

Fig. 4. Histogram representing the estimated number of oospores of Peronospora effusa per seed found in spinach seed lots in three studies. The inset graph focuses on a portion of the histogram for counts below 10 seed lots. Histogram bin width is in increments of 0.2 oospores per seed. 
vortex mixer for $10 \mathrm{~min}$ at full power. The liquid was eluted through one layer of cheesecloth and centrifuged for $10 \mathrm{~min}$ at 4,000 rpm in an Eppendorf 5430 centrifuge. The pellet was resuspended in $500 \mu \mathrm{l}$ of sterile de-ionized water and examined under a light microscope at $100 \times$ magnification for the presence of oospores. Oospores were identified as $P$. effusa by morphological characteristics based on previously described reports (Choi et al. 2007; Inaba et al. 1983; Kunjeti et al. 2016). The results are representative of the average number of oospores observed in three replicates of $75 \mu \mathrm{l}$ of the resuspended pellet. When possible, the diameters of 10 oospores per contaminated seed lot were measured for comparison with previously reported measurements of oospore dimensions (Choi et al. 2007; Inaba et al. 1983; Kunjeti et al. 2016).

Using equation 1 we can calculate the density of oospores per seed in the samples from these studies (Fig. 4). For example, seed lot number 29 from Kunjeti et al. (2016) reported 180 average oospores in one $75-\mu 1$ measurement from a $500-\mu 1$ resuspended pellet from a sample of 1,000 seeds. So the total estimated number of oospores per seed in the seed lot $\left(x_{t}\right)$ is equal to $(180$ oospores $\times[500 \mu \mathrm{l} / 75 \mu \mathrm{l}]) /$ 1,000 seeds, or 1.2 oospores/seed. This is an estimate of the number of oospores per seed, and may differ from the true value due to sampling error, and effectiveness of the oospore-removal process. This method was used to estimate the number of oospores per seed from two previously published studies (Inaba et al. 1983; Kunjeti et al. 2016) and from the new measurements we report here (Supplementary Table S1).

Estimating an optimal phytosanitary threshold for spinach downy mildew. An efficient economic phytosanitary threshold must balance the number of seed lots removed with the amount of inoculum removed. Assume that the total sales value of seed lots in a season is $\$ V$ and the total cost of losses incurred from infections arising from seed in the absence of a phytosanitary threshold is $\$ C$.

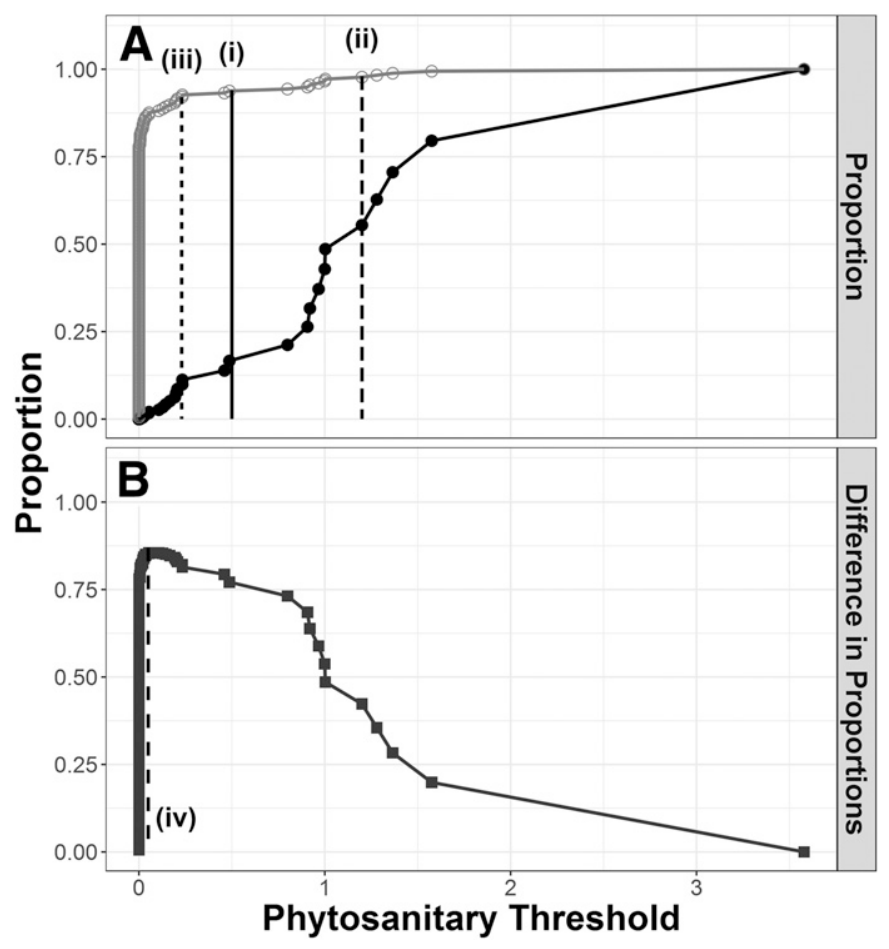

Fig. 5. A, Cumulative distributions for oospores per seed (filled circles) and seed lots (open circles) against increasing mean number of oospores per seed used as potential phytosanitary thresholds. B, The absolute difference between the cumulative distribution curves shown in A. Hypothetical choices for phytosanitary thresholds based on different selection criteria are indicated by vertical lines labeled (i) through (iv). (i) is an arbitrary choice for illustration, (ii) represents an option prioritizing seed producers, (iii) prioritizes growers, and (iv) maximizes the difference between the proportion of oospores removed and the proportion of seed lots rejected. Text provides a complete description.
Further assume that enacting a threshold results in the loss of a proportion, $p_{n}$, of seed lots from the system and a reduction, $r_{n}$, in the proportion of infections. Under these assumptions, economic benefit occurs for all threshold values $(n)$ such that $r_{n} C \geq p_{n} V$, when the cost of potential yield losses outweighs the value of removed seed lots. If it is acceptable to operate the threshold uniformly across the industry, the optimal strategy would be to pick the value $n$, such that the two sides are equal. We can find the value of $n$ by considering the ratio $\rho=V / C$. To balance the production costs saved due to reduced infection and seed value lost we need the ratio $f_{n}=p_{n} / r_{n}=1 / \rho$.

The lost value in rejected seed, $V$, represents a cost to the seed industry, while the costs of infection, $C$, represent losses to the production industry. It is not clear that balancing these two values will be practical or politically desirable; in any case, depending on the economics of production for any given crop a feasible value for $f_{n}$ may not be obtainable. Here, the analysis provides a rationale for making objective decisions; a number of alternative, objective starting points for similar rational discussion can also be selected from the analysis. For example, taking Figure $5 \mathrm{~A}$ as the starting point, one could choose any one of three factors as the most important for driving decision-making: a threshold value of oospores/seed, a proportion of seed lots to be retained, or a proportion of pathogen seed-borne inoculum to be removed.

Scenario i: Regulatory approach. In some cases, seed thresholds for pathogen contamination are set arbitrarily based on approximations or similar pathosystems. In the case of spinach downy mildew, selecting a threshold of 0.5 oospores per seed would result in approximately $15 \%$ of the potential oospore population on seed being accepted, and $94 \%$ of seed lots being passed for sale. This example is indicated by the vertical solid line rooted at 0.5 on the abscissa in Figure 5A, and passing upward through the cumulative distribution curves for seed lots and oospore seed population density.

Scenario ii: Benefit seed producers. Seed thresholds directly cost seed producers by increasing the number of rejected seed lots. Setting a loose threshold that reduces the number of rejected seed lots can help offset these costs while still reducing the amount of introduced inoculum. This example is indicated by the long-dashed lines (marked ii) in Figure 5A, where a target of retention of $98 \%$ of seed lots is selected, resulting in acceptance of $55 \%$ of potential pathogen inoculum; the screening threshold is 1.2 oospores per seed.

Scenario iii: Benefit growers. Seed thresholds directly benefit growers by reducing the amount of inoculum on seeds. Selecting a stricter threshold reduces the amount of inoculum, but increases the number of rejected seed lots. A Fermi approximation (see above) can help determine a regional target for pathogen population reduction (Fig. 5A). Locate the value of the target on the y-axis and draw a horizontal line until it intersects with the pathogen population cumulative density function (CDF). Project vertically upward until the projection intersects with the seed lot CDF to reveal the fraction of seed lots that will be retained as a consequence, while projecting downward to intersect with the $\mathrm{x}$-axis will indicate the operational phytosanitary threshold (oospores/seed) required to achieve the target. This example is indicated by the short dotted black lines in Figure 5A in which a target of $90 \%$ of pathogen inoculum is removed. The proportion of remaining pathogen inoculum $(10 \%$, or 0.1$)$ is located on the y-axis, and requires a rejection of $8 \%$ of seed lots and a screening threshold of 0.23 oospores/seed.

Scenario iv: Maximize proportional difference. Calculate the difference between the CDFs for the pathogen inoculum and seed lots (Fig. 5B). For a convex CDF for seedborne inoculum and concave $\mathrm{CDF}$ for seed lots, the difference has a maximum value. Selecting this maximum results in an operational screening threshold that, on average, maintains the largest possible differential between proportional loss of seeds lots and removal of pathogen 
inoculum. Based on the available data for spinach seed, this corresponds to a threshold of 0.05 oospores per seed and results in the removal of $98 \%$ of the pathogen inoculum and $13 \%$ of the seed lots.

Operational thresholds depend on a concave trade-off between the proportion of seed lots rejected and the proportion of pathogen inoculum removed. The empirical trade-off in the case of the $P$. effusa oospore data used in this study is shown in Figure 6. The key point, also indicated by the location of the maximum value in Figure $5 \mathrm{~B}$, is that the proportion of pathogen inoculum removed is much larger than the proportion of seed lots removed over the initial section of the relationship; large gains in pathogen exclusion for relatively small losses of seed must be possible.

Prioritizing landscape reduction in infection. In scenario iii given above, we indicated that priority could be given to reducing the burden of infection arising from contaminated seed when setting the phytosanitary threshold. We can estimate the total number of potential infections in the landscape using equation 2. Total infections depend on the number of propagules in all seed lots and the number of seeds expected to be planted in the region. Based on the seed lots used in our study, 22\% of the seed lots had observable oospores, and the mean number of oospores in infested seed lots was estimated as 0.45 oospores per seed. Spinach has a germination rate of approximately $90 \%$ (Katzman et al. 2001), and is seeded at 8 to 9 million seeds per hectare (Koike et al. 2011), with approximately 7,300 ha of organic spinach in the United States (USDA-NASS 2015), mostly concentrated in coastal California and the deserts of southern California and western Arizona.

Estimating the infection rate of $P$. effusa oospores is difficult, as there are no studies that have directly demonstrated oospore infection. The factors involved in oospore germination are not uniform across the Peronosporaceae, and can include light, host exudates, and age of the oospore (Forster et al. 1983; van der Gaag and Frinking 1997). A study of $P$. effusa in Japan (Inaba et al. 1983) measured both the number of oospores in seed lots and the number of infected seedlings that emerged from the infested seed lots. A linear regression of these two values (Supplementary Fig. S1) suggests that there were approximately 1.5 infection events for every hundred oospores in a seed lot. These data, along with recent population genetic data suggesting diversity in U.S. populations of $P$. effusa (Lyon et al. 2016), indicate a role for oospores in spinach downy mildew epidemiology. Assuming a 1.5\% infection rate based on data collected by Inaba et al. (1983), we can estimate that the total number of infections caused by oospores is approximately $8.8 \times 10^{7}$ annually in $\mathrm{U}$. S. spinach production. A phytosanitary threshold at 0.23 oospores per seed would reduce the number of infested seed lots to approximately $8 \%$ and the average number of oospores to 0.063 oospores per seed in infested seed lots. These reductions result in an estimated $4.5 \times 10^{6}$ infections over the entire United States. While direct oospore infection in $P$. effusa has not been observed, changing the infection rate used in equation 2 by an order of magnitude would still result in large numbers of potential primary infections in the United States.

Using equation 3 , we can estimate the proportional risk factor for both the untreated group of seed lots and the set of seed lots after using a phytosanitary threshold. We can use $\theta$ to estimate the relative effect of different management strategies by comparing the untreated proportional risk factor $\left(\theta_{u}\right)$ and the treated proportional risk factor $\left(\theta_{t}\right)$ to determine the proportional change effect of different management strategies. For example, if there are an average of 0.45 oospores per seed in $22 \%$ of all seed lots, and a 0.23 oospore per seed threshold reduced those levels to an average of 0.056 oospores per seed in $8 \%$ of seed lots, we could compare the $\theta_{u}$ and $\theta_{t}$ values as

$$
\frac{0.45 \times 0.22}{0.056 \times 0.08}
$$

or 19.6, meaning that the untreated strategy has approximately $20 \times$ more risk of epidemic development.
Cost of mitigation for oospore infested seed lots. The worldwide movement of spinach seeds is extremely valuable, because most modern varieties are hybrids that can only be produced in a few regions of the world (Koike et al. 2011). Roughly $70 \%$ of world spinach seed is produced in Denmark, with another $20 \%$ produced in Washington state in the United States (Morelock and Correll 2008). Most commercial spinach production in the United States is grown as baby-leaf clipped spinach, where the plants are grown at high density for approximately 30 days and then harvested. At a seeding density of approximately 8 to 9 million seeds per hectare (Koike et al. 2011), on approximately 7,300 ha of organic spinach in California and Arizona (USDA-NASS 2015), and at an estimated price of $\$ 450$ per million seeds (Tourte et al. 2015), the estimated value of organic spinach seed sold annually in the United States is $\$ 32.4 \mathrm{M}$.

All mitigation tactics require information about the contamination status of the tested seed lots. The costs of testing spinach seed lots for downy mildew oospores are relatively inexpensive. The necessary consumables (e.g., tubes, cheesecloth, microscope slides) are inexpensive and the equipment (e.g., centrifuge) is common to many testing facilities. The largest expense would be man-hours, as the microscopic examination of oospores in seed wash requires specialized skills. In our scenario, the costs of testing would uniformly affect all management strategies, as all of the described strategies would require information on the contamination status of the seed lots. There are several mitigation tactics to reduce the proportional risk of oospore infection in organic seeds.

Removal of contaminated seed lots. The simplest and most costly tactic is to remove contaminated seed lots from the market. This tactic has the advantage of guaranteed removal of oospore infection risk from those seeds. However, while the economic costs associated with removal of contaminated lots vary depending on the chosen threshold (Fig. 7), this tactic might be too costly for most commercial seed producers. While infested seed lots may be discarded after a phytosanitary inspection to meet the objective of reducing the spread of pathogens, this might be a great economic burden on seed companies and on growers with reduced seed availability and crop production. The cost of removal of contaminated seed lots is calculated by multiplying the cost of organic seed by the number of seeds planted per acre, the number of

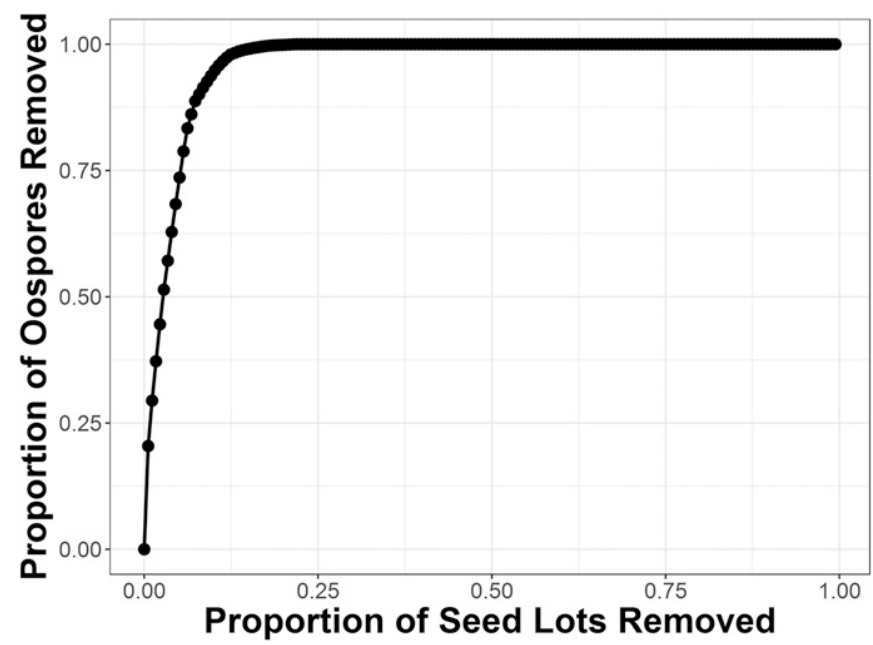

Fig. 6. The relationship between the proportions of seed lots removed (rejected) and the proportions of oospores removed as a function of using the mean number of oospores per seed as a threshold for rejection. The curve is derived from the data in Figure 5. The top right corner corresponds to setting the threshold at 0 oospores/seed (all seed lots rejected, all oospores removed) and the maximum observed value, 3 oospores/seed, corresponds to the bottom left corner (no seed lots rejected, no oospores removed). 
organic acres, and the proportion of seed lots that are contaminated given a set threshold.

Seed treatment. Several seed treatment methods have been developed, including physical treatments (e.g., steam, hot water, surface maceration), chemical controls (e.g., fungicides, bleach), and biological control (e.g., plant growth promoting microbes) (Munkvold 2009). These control tactics have different efficacies and impacts on seed germination. While biological control through the use of beneficial microbes is promising as a seed treatment, it often does not have the same efficacy or consistency as other means of control (du Toit et al. 2009, 2010). The cost of organic seed treatments is estimated to be approximately $\$ 0.10$ per 1,000 seeds (R. A. Choudhury, K. A. Garrett, S. Klosterman, K. Subbarao, and N. McRoberts, unpublished data). The cost of treating contaminated seed lots is calculated by multiplying the price of treatment by the number of seeds planted per acre, the number of organic acres, and the proportion of seed lots that are contaminated given a set threshold.

Sell as conventional. Conventional spinach is worth approximately one third of the value of organic spinach (USDA-NASS 2015), therefore we estimate that the value of conventional seed is roughly $\$ 150$ per one million seeds. Synthetic pesticides effectively manage downy mildew in conventional spinach. However, there are a few drawbacks to this tactic. Many organic varieties are selected solely for downy mildew resistance and may not have optimal horticultural properties. This may limit their use in the conventional market. In addition, while conventional spinach is successfully controlled using synthetic pesticides, exposing seed lots that are heavily infested with $P$. effusa oospores to synthetic fungicides may increase the risk of selection for fungicide resistance in $P$. effusa populations (McDonald and Linde 2002). The cost of selling contaminated seed lots as conventional is calculated by multiplying the difference between the cost of organic seed and conventional seed by the number of seeds planted per acre, the number of organic acres, and the proportion of seed lots that are contaminated given a set threshold.

Costs. We estimate that given a threshold of approximately 0.23 oospores per seed, removal of affected seed lots would cost $\sim \$ 2.7 \mathrm{M}$ (Fig. 7), conversion of organic seed to conventional seed would cost $\sim \$ 1.8 \mathrm{M}$, and seed treatment would cost $\sim \$ 0.6 \mathrm{M}$. While these

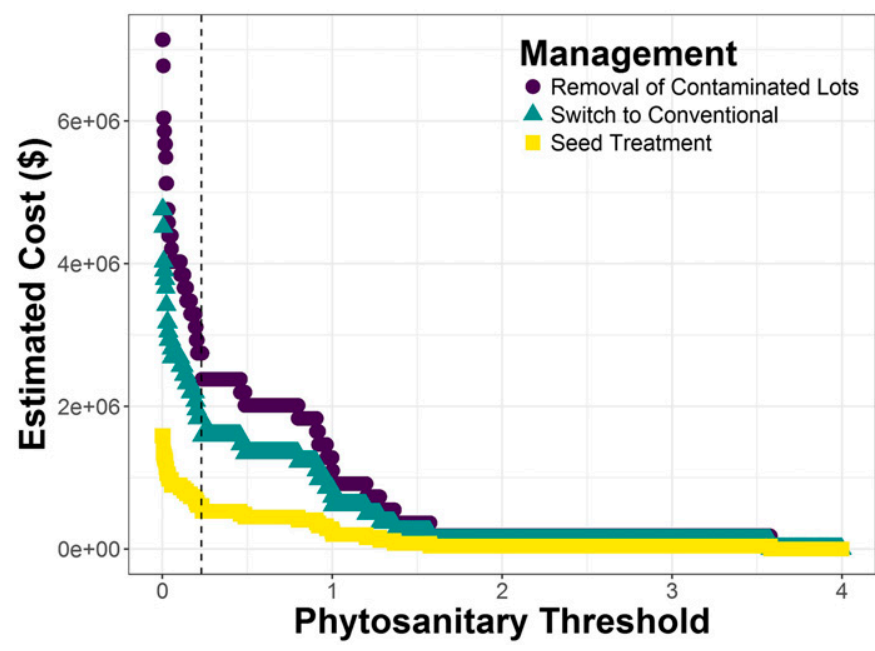

Fig. 7. Outcomes from a model estimating the economic costs of implementing three management tactics across phytosanitary threshold levels of allowable oospores per seed in spinach seed lots. Management tactics are removal of contaminated seed lots (dark circles), switching infested organic seed lots to conventional production (gray triangles), and treating seed lots to prevent oospore success (light gray squares). Dotted vertical line indicates a threshold of 0.23 oospores per seed, which removes $90 \%$ of oospores from the affected seed lots. numbers suggest that seed treatment is the most cost-effective route for long-term disease control, the efficacy of different mitigation strategies could impede success, or even create worse situations. Organic seed treatments can have mixed or unreliable efficacy when compared with conventional synthetic pesticide treatments (du Toit et al. 2009, 2010; Cummings et al. 2008). Additionally, some organic seed treatments can reduce germination in spinach seeds (du Toit and Hernandez-Perez 2005). Selling diseased organic seeds to conventional growers may concentrate heavily infested seed lots in one region or area. In addition, if fields grown from seed lots that are heavily infested with oospores are sprayed with conventional synthetic fungicides, the risk of developing fungicide resistance increases.

An ideal solution may involve combining multiple mitigation methods based on their respective efficacy. If we assume that removal of infested seed lots is the most efficacious way to reduce risk from oospore infection, and that organic seed treatment is a less costly solution compared with switching organic seeds to conventional production, then a more ideal strategy might involve complete removal of heavily infested seed lots and seed treatment of lightly infested seed lots. For example, complete removal of heavily infested seed lots (e.g., over 1.2 oospore per seed) and seed treatment of moderately infested seed lots (e.g., seeds with more than 0.23 and less than 1.2 oospore per seed) would cost $\sim \$ 1.2 \mathrm{M}$ (Fig. $6)$, roughly half the cost of complete removal of all seed lots with $>0.23$ oospores per seed. Optimizing the different strategies depends largely on the efficacy of the mitigation strategies and the costs associated with each. Our current estimation of proportional risk $(\theta)$ does not directly factor in control strategy efficacy or long-term unintended consequences posed by treatments. Future work estimating these parameters would help guide mitigation practices.

\section{CONCLUSIONS, CHALLENGES, AND FUTURE PROSPECTS}

Using a phytosanitary threshold to reduce the number of oosporeinfested spinach seed lots has both costs and benefits. Complete removal of oospore-infested seed lots will greatly reduce the overall risk of the emergence of new pathogen races, but will cost the spinach industry a large portion of the usable seeds. The essential choice entailed in setting a phytosanitary threshold is how to balance seed producer and grower risks. Scenarios ii and iii in our analysis highlight the issue. Scenario ii illustrates a high acceptance rate of seed lots, and scenario iii illustrates a low transmission of seedborne inoculum. The seed producers' general goal for setting a threshold is that seed lots with low levels of contamination have a low probability of being rejected. The seed buyers' goal is to ensure that seed lots with a high level of pathogen inoculum are rejected with a high probability. Our aim was to illustrate the general conditions under which these partially competing objectives can be satisfied and how empirical data from small-scale studies can be used as the basis for discussion. Madden et al. (2007) provide a useful review of how producers' and buyers' risks can be used to design a formal sampling plan that will satisfy the competing requirements, and tools such as SeedCalc (Remund et al. 2001) can help to calculate the acceptable levels of risk for such a sampling plan.

The overall pattern of pathogenic race emergence and the reduction in available resistant spinach germplasm (Correll et al. 2011) suggests that spinach downy mildew is becoming a more serious threat. If new varieties do not remain resistant to downy mildew long enough to recoup the cost of their development, organic spinach production will become unprofitable and unsustainable. The recent history of the industry suggests that new resistance types are frequently overcome after only a single field season, limiting their commercial lifespan. This suggests that without changes in the production system to account for managing pathogen population 
diversity and disease, U.S. organic spinach production may disappear completely, as currently practiced. Reducing and delaying the emergence of new pathogenic races will require coordination, communication and cooperation between growers and seed producers.

The disease challenges facing spinach are a microcosm of agriculture in general. Recent changes in agronomic conditions, such as denser planting and a movement toward organic products with lower tolerances for cosmetic damage, have occurred in many crops. These changes are frequently driven by new markets and reduced quantities of suitable irrigation water and arable land. In parallel with these recent agronomic changes, increasing globalization of agriculture and trade has increased the threat of widespread movement of virulent pathogens. Trade networks across the world connect previously isolated regions, increasing the threat of global plant pathogen pandemics (Xing et al. 2017).

Many seed systems exist as global networks of seed producers, breeders, and germplasm repositories. To make these systems resilient and adaptable to the introduction of new pathogens and pests (Garrett et al. 2017), phytosanitary thresholds should be set appropriately for each region in seed system networks. The level of phytosanitary thresholds could even be adjusted based on the position of a region in larger epidemic networks (Hernandez Nopsa et al. 2015). Phytosanitary thresholds could be especially valuable for less formal seed systems, where seed is traded between local growers and maintained by local nongovernmental organizations. While overly strict phytosanitary thresholds may negatively impact these less formal systems, strategic phytosanitary thresholds could have a net benefit for the system as a whole.

Ultimately, reducing the amount of seedborne inoculum can help in both short- and long-term disease management. This paper provides a framework for optimizing phytosanitary thresholds for endemic pathogens that is relatively flexible depending on the data constraints of a new system. It is important to remember that these thresholds are regionally- and temporally-specific, and may need to be updated if agronomic or climatic conditions change in a region. Phytosanitary thresholds and quality-declared seeds are a necessary management strategy for sustainable agricultural production in many systems.

\section{ACKNOWLEDGMENTS}

We thank the California Leafy Greens Research Program (CLGRP), USDANIFA Hatch project (CA-D- PPA-2131- H), and the California Department of Agriculture Specialty Crop Block Grant Program (Number SCB14043) for funding this research. We thank C. Buddenhagen, R. M. Davis, J. Leveau, and N. Maharaj and two anonymous reviewers for helpful comments and discussion.

\section{LITERATURE CITED}

Atallah, Z. K., Maruthachalam, K., du Toit, L., Koike, S. T., Davis, R. M., Klosterman, S. J., Hayes, R. J., and Subbarao, K. V. 2010. Population analyses of the vascular plant pathogen Verticillium dahliae detect recombination and transcontinental gene flow. Fungal Gen. Biol. 47:416-422.

Atallah, Z. K., Maruthachalam, K., and Subbarao, K. V. 2012. Sources of Verticillium dahliae affecting lettuce. Phytopathology 102:1071-1078.

Brennan, J. P., Warham, E. J., Byerlee, D., and Hernandez-Estrada, J. 1992. Evaluating the economic impact of quality-reducing, seed-borne diseases: Lessons from Karnal bunt of wheat. Agric. Econ. 6:345-352.

Buddenhagen, C. E., Hernandez Nopsa, J. F., Andersen, K. F., Andrade-Piedra, J., Forbes, G. A., Kromann, P., Thomas-Sharma, S., Useche, P., and Garrett, K. A. 2017. Epidemic network analysis for mitigation of invasive pathogens in seed systems: Potato in Ecuador. Phytopathology 107:1209-1218.

Choi, Y.-J., Hong, S.-B., and Shin, H.-D. 2007. Re-consideration of Peronospora farinosa infecting Spinacia oleracea as distinct species, Peronospora effusa. Mycol. Res. 111:381-391.

Choudhury, R. A., Koike, S. T., Fox, A. D., Anchieta, A., Subbarao, K. V., Klosterman, S. J., and McRoberts, N. 2016. Season-long dynamics of spinach downy mildew determined by spore trapping and disease incidence. Phytopathology 106:1311-1318.

Correll, J. C., Bluhm, B. H., Feng, C., Lamour, K., du Toit, L. J., and Koike, S. T. 2011. Spinach: Better management of downy mildew and white rust through genomics. Eur. J. Plant Pathol. 129:193-205.
Cummings, J., du Toit, L., and Miles, C. 2008. Evaluation of seed and drench treatments for organic management of soilborne diseases of spinach in Sequim, WA, 2007. Plant Dis. Manage. Rep. 2:V133.

Cunniffe, N. J., Cobb, R. C., Meentemeyer, R. K., Rizzo, D. M., and Gilligan, C. A. 2016. Modeling when, where, and how to manage a forest epidemic, motivated by sudden oak death in California. Proc. Natl. Acad. Sci. 113: 5640-5645.

Danielsen, S., Mercado, V. H., Ames, T., and Munk, L. 2004. Seed transmission of downy mildew (Peronospora farinosa f. sp. chenopodii) in quinoa and effect of relative humidity on seedling infection. Seed Sci. Technol. 32:91-98.

du Toit, L., Derie, M., Brissey, L., and Holmes, B. 2010. Evaluation of seed treatments for management of seedborne Verticillium and Stemphylium in spinach, 2009. Plant Dis. Manage. Rep. 4:ST038.

du Toit, L., Derie, M., Brissey, L., Holmes, B., and Gatch, E. 2009. Evaluation of seed treatments for management of seedborne Verticillium in spinach, 2008. Plant Dis. Manage. Rep. 3:ST020.

du Toit, L. J., and Hernandez-Perez, P. 2005. Efficacy of hot water and chlorine for eradication of Cladosporium variabile, Stemphylium botryosum, and Verticillium dahliae from spinach seed. Plant Dis. 89:1305-1312.

Edge, D. R. M., and Dirks, M. K. 1983. Problem solving, Enrico Fermi and the Bull Moose. Sch. Sci. Math. 83:601-608.

Epanchin-Niell, R. S. 2017. Economics of invasive species policy and management. Biological Invasions. Springer International Publishing.

Epanchin-Niell, R. S., and Hastings, A. 2010. Controlling established invaders: Integrating economics and spread dynamics to determine optimal management. Ecol. Lett. 13:528-541.

Forster, H., Ribiero, O. K., and Erwin, D. C. 1983. Factors affecting oospore germination of Phytophthora megasperma f. sp. medicaganis. Phytopathology 73:442-448.

Gabrielson, R. L. 1988. Inoculum thresholds of seedborne pathogens: Fungi. Phytopathology 78:868-872.

Garrett, K. A., Andersen, K. F., Asche, F., Bowden, R. L., Forbes, G. A., Kulakow, P. A., and Zhou, B. 2017. Resistance genes in global crop breeding networks. Phytopathology 107:1268-1278.

Geng, S., Campbell, R., Carter, M., and Hills, F. 1983. Quality-control programs for seedborne pathogens. Plant Dis. 67:236-242.

Gilligan, C. A., and van den Bosch, F. 2008. Epidemiological models for invasion and persistence of pathogens. Annu. Rev. Phytopathol. 46: 385-418.

Gitaitis, R., and Walcott, R. 2007. The epidemiology and management of seedborne bacterial diseases. Annu. Rev. Phytopathol. 45:371-97.

Goss, E. M. 2015. Genome-enabled analysis of plant-pathogen migration. Annu. Rev. Phytopathol. 53:121-135.

Grogan, R. G. 1980. Control of lettuce mosaic with virus-free seed. Plant Dis. 64:446-449.

Grünwald, N. J., and Goss, E. M. 2011. Evolution and population genetics of exotic and re-emerging pathogens: Novel tools and approaches. Annu. Rev. Phytopathol. 49:249-267.

Henson, S., and Loader, R. 2001. Barriers to agricultural exports from developing countries: The role of sanitary and phytosanitary requirements. World Dev. 29:85-102.

Hernandez Nopsa, J. F., Daglish, G. J., Hagstrum, D. W., Leslie, J. F., Phillips, T. W., Scoglio, C., Thomas-Sharma, S., Walter, G. H., and Garrett, K. A. 2015. Ecological networks in stored grain: Key postharvest nodes for emerging pests, pathogens, and mycotoxins. Bioscience 65:985-1002.

Inaba, T., Takahashi, K., and Morinaka, T. 1983. Seed transmission of spinach downy mildew. Plant Dis. 67:1139-1141.

Inderbitzin, P., and Subbarao, K. V. 2014. Verticillium systematics and evolution: How confusion impedes Verticillium wilt management and how to resolve it. Phytopathology 104:564-574.

Islam, M. T., Croll, D., Gladieux, P., Soanes, D. M., Persoons, A., Bhattacharjee, P., Hossain M. S., Gupta, D. R., Rahman, M. M., Mahboob, M. G., Cook, N., Salam, M. U., Surovy, M. Z., Sancho, V. B., Maciel, J. L. N., Mhani, A., Jr., Casroagudin, V. L., Reges, J. T., Ceresini., P. C., Ravel, S., Kellner, R., Rournier, E., Tharreau, D., Llebrun, M.-H., McDonald, B. A., Stitt, T., Swan, D., Talbot, N. J., Saunders, D. G. O., Win, J., and Kamoun, S. 2016. Emergence of wheat blast in Bangladesh was caused by a South American lineage of Magnaporthe oryzae. BMC Biol. 14:84.

Katzman, L. S., Taylor, A. G., and Langhans, R. W. 2001. Seed enhancements to improve spinach germination. HortScience 36:979-981.

Klosterman, S. J. 2016. Spinach downy mildew-Threat, prevention and control. Prog. Crop Consult. 1:12-15.

Koike, S., Cahn, M., Cantwell, M., Fennimore, S., Lestrange, M., Natwick, E., Smith, R. F., and Takele, E. 2011. Spinach production in California. Univ. Calif. Agric. Nat. Resour. Publ. 7212.

Kuan, T. L. 1988. Inoculum thresholds of seedborne pathogens. Overview. Phytopathology 78:867-868. 
Kunjeti, S. G., Anchieta, A., Subbarao, K. V., Koike, S. T., and Klosterman, S. J. 2016. Plasmolysis and vital staining reveal viable oospores of Peronospora effusa in spinach seed lots. Plant Dis. 100:59-65.

Lamour, K. H., Mudge, J., Gobena, D., Hurtado-Gonzales, O. P., Schmutz, J., Kuo, A., Miller, N. A., Rice, B. J., Raffaele, S., Cano, L. M., Bharti, A. K., Donahoo, R. S., Finley, S., Huitema, E., Hulvey, J., Platt, D., Salamov, A., Savidor, A., Sharma, R., Stam, R., Storey, D., Thines, M., Win, J., Haas, B. J., Dinwiddie, D. L., Jenkins, J., Knight, J. R., Affourtit, J. P., Han, C. S., Chetkov, O., Linduist, E. A., Detter, C., Grigoriev, I. V., Kamoun, S., and Kingsmore, S. F. 2012. Genome sequencing and mapping reveal loss of heterozygosity as a mechanism for rapid adaptation in the vegetable pathogen Phytophthora capsici. Mol. Plant-Microbe Interact. 25:1350-1360.

Lyon, R., Correll, J., Feng, C., oBluhm, B., Shrestha, S., Shi, A., and Lamour, K. 2016. Population structure of Peronospora effusa in the Southwestern United States. PLoS One 11:e0148385.

Madden, L. V., Hughes, G., and van den Bosch, F. 2007. The Study of Plant Disease Epidemics. American Phytopathological Society, St. Paul, MN.

Marshall, D., Work, T. T., and Cavey, J. F. 2003. Invasion pathways of Karnal bunt of wheat into the United States. Plant Dis. 87:999-1003.

McDonald, B. A., and Linde, C. 2002. Pathogen population genetics, evolutionary potential, and durable resistance. Annu. Rev. Phytopathol. 40: 349-79.

McKay, A., Floyd, R., and Boyd, C. 1992. Phosphonic acid controls downy mildew (Peronospora parasitica) in cauliflower curds. Anim. Prod. Sci. 32: 127-129.

Meentemeyer, R. K., Haas, S. E., and Vaclavik, T. 2012. Landscape epidemiology of emerging infectious diseases in natural and human-altered ecosystems. Annu. Rev. Phytopathol. 50:379-402.

Morelock, T., and Correll, J. 2008. Spinach. Pages 189-218 in: Handbook of Plant Breeding: Vegetables I. J. Prohens and F. Nuez, eds. Springer, New York.

Munkvold, G. P. 2009. Seed pathology progress in academia and industry. Annu. Rev. Phytopathol. 47:285-311.

Pryor, B., Davis, R. M., and Gilbertson, R. L. 1994. Detection and eradication of Alternaria radicina on carrot seed. Plant Dis. 78:452-456.

Remund, K. M., Dixon, D. A., Wright, D. L., and Holden, L. R. 2001. Statistical considerations in seed purity testing for transgenic traits. Seed Sci. Res. 11:101-119.

Roberts, S. J. 1999. Thresholds, standards, tests, transmission and risks. Pages 20-24 in: Proceedings of the 3rd ISTA Seed Health Symposium. J. W. Sheppard, ed. Ames, IA, USA ISTA, Zurich, Switzerland.

Russell, T. S. 1988. Some aspects of sampling and statistics in seed health testing and the establishment of threshold levels. Phytopathology 78:880-881.

Schaad, N. W. 1988. Inoculum thresholds of seedborne pathogens. Bacteria. Phytopathology 78:872-875.
Short, D. P. G., Gurung, S., Koike, S. T., Klosterman, S. J., and Subbarao, K. V. 2015a. Frequency of Verticillium species in commercial spinach fields and transmission of $V$. dahliae from spinach to subsequent lettuce crops. Phytopathology 105:80-90.

Short, D. P. G., Gurung, S. G., Gladieux, P., Inderbitzin, P., Atallah, Z. K., Nigro, F., Li, G., Benlioglu, S., and Subbarao, K. V. 2015b. Globally invading populations of the fungal plant pathogen Verticillium dahliae are dominated by multiple divergent lineages. Environ. Microbiol. 17:2824-2840.

Sperling, L., Ortiz, O., and Thiele, G. 2013. RTB Seed Systems. Conceptual frameworks for guiding practical interventions. Working Paper 2013-1. CGIAR Research Program on Roots, Tubers and Bananas.

Stace-Smith, R., and Hamilton, R. 1988. Inoculum thresholds of seedborne pathogens: Viruses. Phytopathology 78:875-880.

Stansbury, C. D., McKirdy, S. J., Diggle, A. J., and Riley, I. T. 2002. Modeling the risk of entry, establishment, spread, containment, and economic impact of Tilletia indica, the cause of Karnal bunt of wheat, using an Australian context. Phytopathology 92:321-331.

Stukenbrock, E. H., and McDonald, B. A. 2008. The origins of plant pathogens in agro-ecosystems. Annu. Rev. Phytopathol. 46:75-100.

Thomas-Sharma, S., Abdurahman, A., Ali, S., Andrade-Piedra, J., Bao, S., Charkowski, A., Kadian, M., Kromann, P., Struik, P. C., Torrance, K., Garrett, K. A., and Forbes, G. A. 2016. Seed degeneration in potato: The need for an integrated seed health strategy to mitigate the problem in developing countries. Plant Pathol. 65:3-16.

Tourte, L., Smith, R. F., Klonsky, K., Sumner, D., Tumber, K. P., and Stewart, D. 2015. Sample costs to produce and harvest organic spinach. University of California Cooperative Extension. https://coststudyfiles.ucdavis.edu/ uploads/cs_public/79/02/79023ea8-80a8-4fba-b69e-5d60225dbf8b/2015_ organicspinach-finaldraftjan29.pdf

USDA-NASS. 2015. 2012 census of agriculture: organic survey (2014). Volume 3, Special Studies, Part 4 (AC-12-SS-4). United States Department of Agriculture National Agricultural Statistics Service.

van der Gaag, D. J., and Frinking, H. D. 1997. Factors affecting germination of oospores of Peronospora viciae f. sp. pisi in vitro. Eur. J. Plant Pathol. 103: 573-580.

Wisler, G. C., and Duffus, J. E. 2000. A century of plant virus management in the Salinas Valley of California, 'East of Eden'. Virus Res. 71:161-169.

Wu, B. M., and Subbarao, K. V. 2014. A model for multiseasonal spread of Verticillium wilt of lettuce. Phytopathology 104:908-917.

Xing, Y., Hernandez Nopsa, J., Andrade-Piedra, J., Beed, F., Blomme, G., Carvajal Yepes, M., Coyne, D., Forbes, G., Kreuze, J., Kroschel, J., Kumar, L., Legg, J., Parker, M., Schulte-Geldermann, E., and Garrett, K. A. 2017. Global cropland connectivity: A risk factor for invasion and saturation by emerging pathogens and pests. bioRxiv Article 106542. doi:10.1101/106542 